\title{
DIAGNÓSTICO DA SITUAÇÃO ATUAL DA ADOÇÃO DOS SISTEMAS INTEGRADOS DE GESTÃO (ERP) NAS MICRO E PEQUENAS EMPRESAS BRASILEIRAS PESQUISADAS
}

Fabio Rios Stumpf ${ }^{1}$

André Yves Cribb ${ }^{2}$

${ }^{1}$ Universidade Federal Rural do Rio de Janeiro

${ }^{2}$ Embrapa Agroindústria de Alimento 


\section{DIAGNÓSTICO DA SITUAÇÃO DA ADOÇÃO DOS SISTEMAS \\ INTEGRADOS DE GESTÃO (ERP) NAS MICRO E PEQUENAS EMPRESAS BRASILEIRAS}

\section{Resumo}

A adoção de sistemas integrados de gestão ERP, tem sido cada vez mais difundida e os estudos sobre o processo de adoção e o impacto da tecnologia têm recebido grande destaque nos últimos anos. Focando nas micro e pequenas empresas (MPE) brasileiras, do ponto de vista do receptor da tecnologia, o presente estudo, pesquisou 411 empresas durante o segundo semestre de 2016. Na pesquisa survey, aqui relatada, buscou-se diagnosticar a situação atual da adoção desses sistemas, além de analisar os motivos da não adoção, módulos adotados, nível de satisfação e suas experiências sobre o tema. Os resultados obtidos demonstraram que apenas pouco mais de $51 \%$ das micro e pequenas empresas brasileiras possuem um sistema integrado de gestão ERP. Espera-se que este estudo possa auxiliar empresários e governos a planejarem ações mais eficientes, investimentos e políticas públicas relacionadas à adoção de tais tecnologias.

Palavras-chave: Adoção de Tecnologia, Inovação, Micro e Pequenas Empresas, MPE, ERP.

\section{Introdução}

As micro e pequenas empresas (MPE) brasileiras sofrem fortes pressões competitivas, e segundo Oliveira, Santos e Junior (2013), as mudanças tecnológicas têm afetado inclusive a sobrevivência das MPE. Por isso, a utilização de tecnologias tem-se tornado necessário e até mesmo crucial para que as mesmas sobrevivam e consigam prosperar. No entanto, esse processo de crescimento e de mudança tecnológica é muitas vezes visto como uma proposta assustadora. Segundo Porter (1999), nesses casos, os gestores enfrentam um alto nível de incerteza sobre as necessidades dos clientes, sobre os produtos e serviços mais desejáveis e sobre a melhor configuração das atividades e tecnologias.

Quanto aos investimentos em adoção de tecnologias de informação, muito executivos veem seus concorrentes implantarem diferentes projetos tecnológicos e acabam fazendo o mesmo, por medo de ficar para trás ou de mobilizar-se tarde demais (LUNARDI, DOLCI E MAÇADA, 2010). No entanto, frequentemente, existe um histórico de tentativas frustradas, investimentos sem um retorno mensurável e até mesmo uma incredulidade da equipe operacional e da direção em relação a eficácia dessas tecnologias (McAFEE, 2004). Esses fatos contribuem, ainda mais, para o aumento desse nível de incerteza e pressões sobre os gestores (LUNARDI, DOLCI E MAÇADA, 2010). Todos esses aspectos aliados à dificuldade de mão de obra capacitada, à falta de capital de giro e linhas de crédito capazes de atender às necessidades dessas organizações quase que inviabilizam esse processo de mudança. Por outro lado, o simples fato de não se abrir às mudanças tem estagnado muitas organizações, quando não proporcionam até a falência das mesmas.

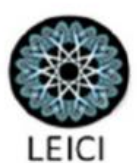


Outro aspecto observado, são os grandes investimentos governamentais na implementação de controles informatizados da arrecadação, como por exemplo: A Nota Fiscal Eletrônica (NF-E) que integrou a emissão das Notas Fiscais em todos os 27 estados da federação; A Nota Fiscal de Serviço Eletrônica (NFS-E) que atualmente já está presente em mais 800 cidades; A Nota Fiscal de Consumidor Eletrônica (NFC-E) que está em processo de implementação em diversos estados brasileiros e tem por cronograma a total implantação até dezembro de 2018, assim como outros sistemas de gestão da arrecadação como SPED, ESOCIAL (RECEITA FEDERAL, 2017). Essas exigências governamentais, de certo modo, proporcionam aos empresários uma obrigatoriedade ao uso dos sistemas integrados de gestão (ERP), mas que por sua vez, precisam ser implementados a fim de realmente contribuir para o ganho competitivo das empresas e não apenas atender tais exigências.

A medida que os sistemas ERP se tornam mais acessíveis financeiramente, mais rápida é a sua popularização no que diz respeito as empresas menores, dependendo da localização e da natureza do negócio (PALVIA e PALVIA, 1999). Contudo, o aumento do uso, quando observado nas MPE, está concentrado principalmente nas funções operacionais e administrativas, em detrimento das funções estratégicas e de suporte a tomada de decisões (LIMA, 2007). O uso efetivo dessas tecnologias pode proporcionar uma série de ganhos às empresas, como o aumento de produtividade, incremento no faturamento, redução dos custos operacionais, aquisição de novos clientes, decisões assertivas, além da diferenciação de produtos e serviços inovadores (HU e PLANT, 2001).

Observando as especificidades inerentes às MPE, no que tange ao uso de sistemas ERP, Ramos, Silva e Alvarega (2009) consideram que o uso adequado e eficaz só é possível quando o processo de adoção é planejado, onde proprietários e principais usuários têm conhecimento desse processo e das mudanças inerentes e necessárias, bem como das potencialidades e limitações que podem surgir das tecnologias e das pessoas (OLIVEIRA, SANTOS e JÚNIOR, 2013). Nesse sentido, grande parte da literatura sobre adoção de tecnologia concorda com a relevância do tema, entretanto, há poucos estudos de comparação entre os modelos teóricos de adoção de sistemas ERP (OLIVEIRA; MARTINS, 2011; MORAES, TERENCE e ESCRIVÃO FILHO, 2004), principalmente observando os problemas e oportunidades ligadas às MPE que são únicos, e portanto, merecem pesquisas específicas que busquem preencher essas lacunas (LUNARDI, DOLCI, MAÇADA, 2010).

Pesquisas sobre adoção de tecnologias nas MPE podem fornecer um conjunto rico de resultados que podem ser aplicados para melhor compreender o impacto da sua adoção e utilização, hoje fundamentais para que essas empresas possam se tornar mais competitivas no mercado e atender as exigências legais (LUNARDI, DOLCI E MAÇADA, 2010). Porém, o estudo avança quando se compromete a analisar o esse processo do ponto de vista dos adotantes da tecnologia (empresários e colaboradores).

Neste contexto, este trabalho busca responder a seguinte pergunta de pesquisa: Qual a situação atual da adoção de sistemas integrados de gestão (ERP) nas micro e pequenas empresas brasileiras? A fim de responder a pergunta, o objetivo geral do trabalho é diagnosticar a situação da adoção de sistemas ERP nas MPE brasileiras. Além disso, busca-se analisar os motivos da não adoção, módulos adotados, nível de satisfação e suas experiências sobre o tema.

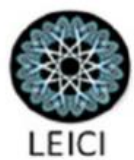


A pesquisa foi realizada por meio de uma abordagem exploratória e descritiva com a aplicação de pesquisa survey, por meio de entrevistas aos proprietários, gerentes, administradores, contadores ou responsáveis das áreas específicas ligadas à gestão ou adoção da nova tecnologia.

O artigo está estruturado da seguinte forma: na seção 2, apresenta-se o referencial teórico da pesquisa, abordando a importância das MPE, caracterizando os sistemas ERP e o processo de adoção de tecnologia; na seção 3, apresenta-se as etapas metodológicas do estudo; na seção 4, apresentam-se os resultados encontrados; e, por fim na seção 5, procede-se com as considerações finais.

\section{Referencial Teórico}

\subsection{A importância das MPE}

Segundo um estudo do SEBRAE (2014) no ano de 2011, as MPE representaram, por número de empresas, $99,2 \%$ no setor de comércio, $98,2 \%$ no setor de serviços, e $95,5 \%$ no setor de indústrias. Em 2011, o IBGE calculou em 27\% a participação dos pequenos negócios no PIB. Ou seja, mais de um quarto do Produto Interior Bruto brasileiro é gerado pelos micro e pequenos negócios. Isso demonstra claramente a importância das MPE na economia brasileira, e esses percentuais justificam os esforços no sentido a incentivar e melhor qualifica-las a fim de alavancar a economia nacional.

A definição das micro e pequenas empresas brasileiras (MPE) pode ser feita de duas formas alternativas. Segundo o SEBRAE (2006): pelo número de pessoas ocupadas na empresa ou pela receita auferida. No primeiro caso, considera-se microempresas, aquelas nas atividades de serviços e comércio com até 9 pessoas ocupadas, e como pequena empresa as que tenham entre 10 e 49 pessoas ocupadas. Na atividade industrial, são microempresas, aquelas com até 19 pessoas ocupadas, e pequenas empresas entre 20 e 99 pessoas ocupadas. No segundo caso, Segundo a Lei Complementar $\mathrm{N}^{\mathrm{o}} 123$, de 14 de dezembro de 2006, que instituiu o Estatuto Nacional da Microempresa e da Empresa de Pequeno Porte, considera-se microempresa, aquelas que aufiram em cada ano-calendário a receita bruta igual ou inferior a $\mathrm{R} \$ 360.000,00$ (trezentos e sessenta mil reais); e no caso da empresa de pequeno porte, aquelas que aufiram em cada ano-calendário a receita bruta superior a $R \$ 360.000,00$ (trezentos e sessenta mil reais) e igual ou inferior a $\mathrm{R} \$ 3.600 .000,00$ (três milhões e seiscentos mil reais).

Na observância das MPE e considerando a conservação de sua saúde a curto e a longo prazo é necessário que as informações sejam processadas gerando relatórios gerenciais, para que estes auxiliem os gestores na tomada de decisão, e é neste contexto que os sistemas ERP devem se fazer ainda mais presente no dia a dia dos gestores e dessas organizações (ALMEIDA et al., 2012).

\subsection{Sistemas integrados de gestão ERP}

Para definir um sistema integrado de gestão faz-se necessário entender o conceito do SIG - Sistema de Informações Gerenciais. De acordo com Batista (2013) e Chopra e Meindl (2016), os sistemas de informações gerenciais trabalham no auxílio da gestão, planejamento e

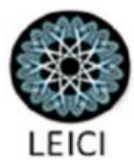


controle de produção. São ferramentas capazes de gerir informações e relacionamentos entre setores, clientes, recursos humanos e fornecedores. Segundo Chopra e Meindl (2016), um sistema integrado de gestão ERP se propõe a dar suporte a todos os processos e áreas funcionais de uma empresa a partir de uma base de dados única, na qual todas as transações estejam interligadas. Ele é composto por módulos integrados que atendem a cada área funcional ou processo, como Finanças, Produção, Custos, Vendas, RH, etc.

Os "Sistemas de Informações Gerenciais" ou também conhecidos como "Sistemas Integrados de Gestão Empresarial" - SIG ou em inglês "Enterprise Resource Planning - ERP" (DAVENPORT, 2000), são a evolução de outra metodologia conhecida como MRP e MRP II (Manufacturing Requeriment Planning). O MRP trata do registro de produção como quantidade de material utilizado, tempo para produção e quantidade produzida para se projetar uma previsão de recursos a serem destinados à produção, quando se investir os recursos e o quanto será produzido. O MRP II que passou a atender às necessidades de informação para a tomada de decisão gerencial sobre todos os recursos de manufatura. Na sequência, novos módulos foram agregados ao MRP II, como por exemplo Gerenciamento dos Recursos Humanos, Vendas e Distribuição, Finanças e Controladoria, ultrapassando os limites da manufatura, percorrendo toda a empresa e chegando ao seu estágio atual de desenvolvimento, caracterizando-se como um Sistema Integrado de Gestão - ERP (CHOPRA e MEINDL, 2016).

O objetivo maior de um sistema ERP é a integração dos dados organizacionais e a sua disponibilização em tempo real. Com isso, ele promete interligar setores, unidades e filiais em diferentes locais, possibilitando a adoção de um único padrão de indicadores para a organização. Davenport (2000) define os sistemas ERP como pacotes de aplicações computacionais que dão suporte a maior parte das necessidades de informação das organizações. Para Souza e Zwicher (2000), os sistemas ERP são pacotes comerciais de softwares que incorporam modelos padrões de processos de negócios (as chamadas "bestpractices"), e requerem procedimentos de ajuste para que possam ser utilizados em uma determinada empresa. Também permitem certa adequação das funcionalidades existentes através da parametrização. Este processo consiste na definição de diversos valores que são introduzidos no sistema com o intuito de dimensionar o perfil da empresa e o comportamento do sistema. A orientação a processos é destacada por muitos autores na caracterização de ERP. Segundo Souza \& Zwicker (2000), os processos de negócio podem ser definidos como um conjunto de tarefas e procedimentos interdependentes realizados para alcançar determinado resultado empresarial, sendo uma de suas características a transposição de fronteiras organizacionais.

\subsection{0 processo de adoção tecnológica}

A adoção de tecnologia, segundo Rogers (2003), é uma etapa crucial para todo o processo de desenvolvimento da inovação. Para Rogers (2003), a adoção se efetiva quando passa a ser adquirida e absorvida pelos adotantes, e no momento que a tecnologia começa a ser adotada por diversos outros adotantes, entende-se que está sendo difundida, transformando as descobertas científicas em prática.

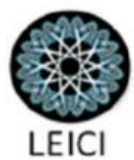


Considerando a adoção de tecnologia como um processo não trivial, pois envolve decisões complexas, arriscadas e incertas, com pouca ou nenhuma garantia de sucesso (SUÁREZ; SILVA; SOUZA, 2011), conhecer as ações a serem tomadas e os problemas a serem enfrentados na adoção de sistemas ERP possibilita aos gestores a prevenção de problemas e a tomada de ações mais acertadas (FREITAS; RECH, 2003). Dessa forma, entender, de forma consistente, o processo de adoção torna-se essencial para a eficácia do processo decisório.

Nesse sentido, dentre as muitas teorias usadas na área de sistemas de informação, Oliveira e Martins (2011), afirmam que as mais usadas para análise da adoção de tecnologia são: o technology acceptance model (TAM), a theory of planned behavior (TPB), unified theory of acceptance and use of technology (UTAUT), diffusion of innovation (DOI) e a technology, organization and environment (TOE).

Comumente, o termo "implantação" é utilizado para expressar o processo de adoção de um sistema ERP, o que de certa forma minimiza o processo de adoção que, segundo Mendes \& Escrivão Filho (2000), envolve as etapas de seleção, aquisição, implantação e testes. No entanto, Cribb et Al (2011) ao explanarem o processo de adoção de tecnologia como um processo dinâmico e integrado, substitui o termo testes por absorção, e afirmam que a adoção tecnológica efetiva é um processo que envolve quatro etapas: seleção, aquisição, implementação (ou implantação) e absorção da tecnologia. Vale ressaltar, que esse termo absorção da tecnologia já tinha sido utilizado por Rogers (2003) para expressas a última etapa do processo de tecnologia. Dessa forma, considera-se esse conceito como um processo que só se efetiva após o cumprimento de todas essas etapas.

Figura 1 - O Processo de Adoção Tecnológica.

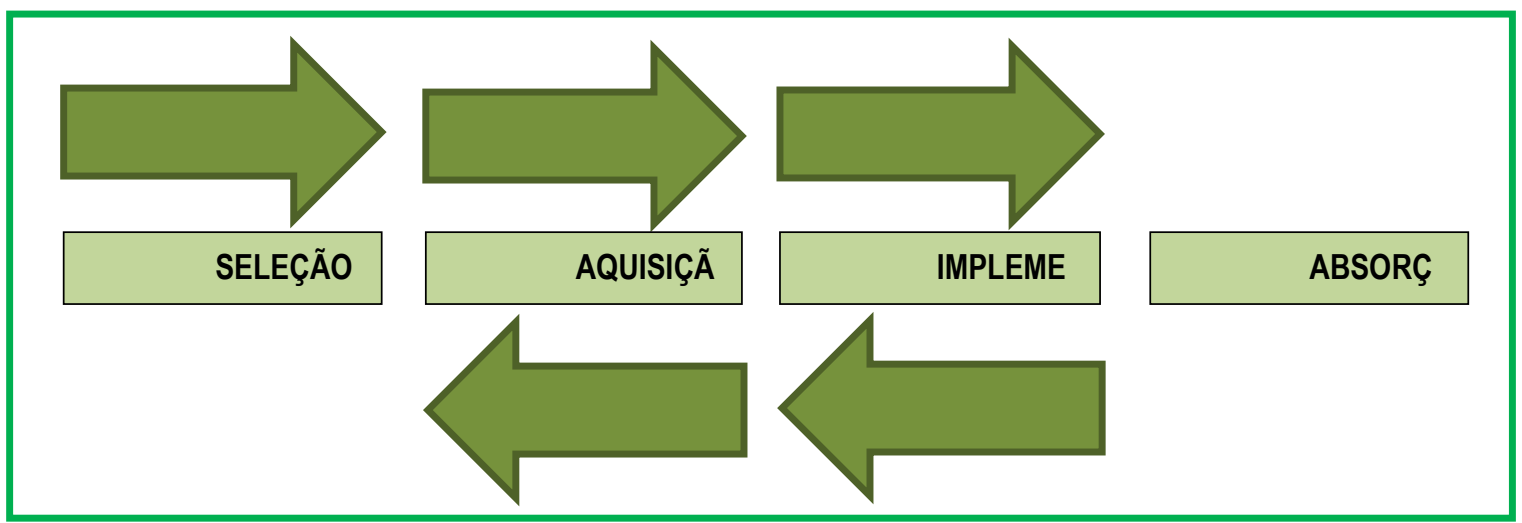

Fonte: Elaborada com base em CRIBB et al. (2011).

Segundo Cribb et Al (2011), a seleção da tecnologia deve ter como alicerce de sua escolha as características da mesma, o seu desempenho, o investimento necessário em relação ao benefício proposto e a capacidade financeira da empresa, perspectivas de mercado e metas de médio e longo prazo. A aquisição da tecnologia por sua vez, pode ocorrer de fonte interna ou externa. Essas tecnologias podem ser adquiridas internamente através de departamentos de TI (Tecnologia da Informação), ou considerando a tendência mundial de terceirização dos 
serviços de TI, essa aquisição pode aproveitar as capacidades das empresas de TI do mercado, a experiência de concorrentes, fornecedores e seus departamentos de $\mathrm{P} \& \mathrm{D}$, ou até mesmo através de acordo contratuais, tais como licenças, acordos de P\&D e joint ventures, etc., (PISANO, 1990). Quanto à implantação da tecnologia selecionada e adquirida é fundamental no processo de adoção tecnológica. Ela supõe a instalação dos componentes físicos, o treinamento do pessoal e a incorporação da tecnologia nas rotinas diárias da unidade produtiva (ROGERS, 2003). Também requer pesquisas e esforços adicionais, além de envolver vários parceiros e exigir coordenação e compromisso destes (HAUSMAN; STOCK, 2003). E por fim, a absorção da tecnologia refere-se à valorização, assimilação e aplicação da tecnologia para fins produtivos. A capacidade de absorção tecnológica pode ser criada como um subproduto dos investimentos em P\&D ou das próprias operações produtivas (COHEN; LEVINTHAL, 1990). Ela influencia positivamente a aquisição de tecnologias internamente ou externamente geradas (HARO DOMÍNGUEZ et al., 2007).

\section{Metodologia}

Este estudo caracteriza-se por uma pesquisa survey com o objetivo de diagnosticar a situação da adoção de sistemas ERP nas MPE brasileiras, analisando os motivos da não adoção, módulos adotados, nível de satisfação e suas experiências sobre o tema. A populaçãoalvo do estudo foram as MPE brasileiras, por meio da opinião de seus proprietários, gerentes, administradores, contadores ou responsáveis das áreas específicas ligadas à gestão ou adoção da nova tecnologia.

O estudo foi realizado no período de 01/07/2016 a 10/02/2017, onde foram aplicados 419 (quatrocentos e dezenove) questionários, sendo descartados 8 (oito) questionários da análise dos dados, uma vez que os mesmos correspondiam a empresas com um faturamento superior a $\mathrm{R} \$ 3.600 .000,00$ (três milhões e seiscentos mil reais), o que descaracterizou essas empresas como MPE. Dos 411 questionários válidos, 241 (58,6\%) eram de microempresas, enquanto $170(41,4 \%)$ eram de pequenas empresas. A amostra vislumbrou empresas de cada unidade federativa do país, a fim de obter dados representativos de todos os estados brasileiros, e é apresentada na tabela 1. Foram considerados estabelecimentos de diversos setores da economia, classificados como industrias, comércios e prestadoras de serviço. $\mathrm{O}$ estudo teve uma orientação quantitativa, englobando os procedimentos de amostragem, coleta, validação e análise dos dados.

O modelo da pesquisa proposto neste estudo está apresentado na figura 2, e foi estruturado um questionário onde foram inseridas questões de caracterização da amostra (como ano de fundação, estado, atividade econômica, número de funcionários, faturamento em 2015, cargo do respondente na empresa); uma questão dicotômica sobre "se já adotaram um sistema ERP?"; caso a questão sobre se adotaram um ERP fosse negativa, uma próxima questão mista apresentada era sobre "quais os motivos pelo qual não possuem um sistema ERP?" com as possíveis respostas: Não tenho condições financeiras para investir; Não vejo necessidade; Faço meus controles através de planilhas; Não conheço uma empresa de confiança; e Outro, caso a questão sobre se adotaram um sistema ERP fosse positiva, uma próxima questão fechada era apresentada sobre "quais módulos estão implementados em sua empresa?" com os seguintes módulos listados: Orçamentos e Propostas; Ponto de Venda;

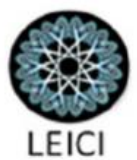


Distribuição; Atendimento a Clientes; Recursos Humanos; Estoque e Suprimentos; Produção; Financeiro, com as possíveis respostas: Não se aplica; Em Implantação; Implementado, em seguida outra questão era apresentada sobre se "você considera que a implantação do sistema ERP foi satisfatória?" em uma escala tipo Likert de 4 pontos (variando de "Totalmente Insatisfatório" a "Totalmente Satisfatório"; E por último a questão "quantos Sistemas ERP já adotou na empresa antes do atual?" em uma escala Likert de 6 pontos (variando de zero a cinco).

Tabela 1 - MPE segmentadas por Estado

\begin{tabular}{|l|r|r|r|r|r|}
\hline Estado & Microempresa & Delta (\%) & Pequena & Delta (\%) & Total \\
\hline Acre & 1 & $50,0 \%$ & 1 & $50,0 \%$ & 2 \\
Alagoas & 1 & $33,3 \%$ & 2 & $66,7 \%$ & 3 \\
Amapá & 0 & $0,0 \%$ & 2 & $100,0 \%$ & 2 \\
Amazonas & 1 & $50,0 \%$ & 1 & $50,0 \%$ & 2 \\
Bahia & 6 & $33,3 \%$ & 12 & $66,7 \%$ & 18 \\
Ceará & 11 & $100,0 \%$ & 0 & $0,0 \%$ & 11 \\
Distrito Federal & 3 & $42,9 \%$ & 4 & $57,1 \%$ & 7 \\
Espírito Santo & 5 & $62,5 \%$ & 3 & $37,5 \%$ & 8 \\
Goiás & 10 & $76,9 \%$ & 3 & $23,1 \%$ & 13 \\
Maranhão & 3 & $60,0 \%$ & 2 & $40,0 \%$ & 5 \\
Mato Grosso & 7 & $100,0 \%$ & 0 & $0,0 \%$ & 7 \\
Mato Grosso do Sul & 2 & $33,3 \%$ & 4 & $66,7 \%$ & 6 \\
Minas Gerais & 31 & $72,1 \%$ & 12 & $27,9 \%$ & 43 \\
Pará & 6 & $100,0 \%$ & 0 & $0,0 \%$ & 6 \\
Paraíba & 1 & $25,0 \%$ & 3 & $75,0 \%$ & 4 \\
Paraná & 26 & $81,3 \%$ & 6 & $18,8 \%$ & 32 \\
Pernambuco & 0 & $0,0 \%$ & 10 & $100,0 \%$ & 10 \\
Piauí & 0 & $0,0 \%$ & 3 & $100,0 \%$ & 3 \\
Rio de Janeiro & 20 & $64,5 \%$ & 11 & $35,5 \%$ & 31 \\
Rio Grande do Norte & 1 & $25,0 \%$ & 3 & $75,0 \%$ & 4 \\
Rio Grande do Sul & 14 & $41,2 \%$ & 20 & $58,8 \%$ & 34 \\
Rondônia & 5 & $71,4 \%$ & 2 & $28,6 \%$ & 7 \\
Roraima & 0 & $0,0 \%$ & 1 & $100,0 \%$ & 1 \\
Santa Catarina & 11 & $50,0 \%$ & 11 & $50,0 \%$ & 22 \\
São Paulo & 74 & $58,7 \%$ & 52 & $41,3 \%$ & 126 \\
Sergipe & 0 & $0,0 \%$ & 2 & $100,0 \%$ & 2 \\
Tocantins & 2 & $100,0 \%$ & 0 & $0,0 \%$ & 2 \\
Total & 241 & $58,6 \%$ & 170 & $41,4 \%$ & 411 \\
\hline For & & 0 & \\
\hline
\end{tabular}

Fonte: Elaborada pelo autor a partir dos dados do IBGE (2014) e dados da pesquisa.

Afirma-se um nível de confiança de $95 \%(Z=1,96)$ aceitando uma margem de erro de $5 \%(\mathrm{E}=0,05)$, uma vez que utilizando a expressão $\left[\mathrm{n}=\left(\mathrm{Z}^{2} * 1 / 4\right) / \mathrm{E}^{2}\right]$, segundo Barbetta (2010), logo $\left[\mathrm{n}=(1,96 * 1 / 4) / 0,05^{2}\right]$, que resulta 396 (trezentos e noventa e seis), como o 
número mínimo de empresas o tamanho mínimo da amostra capaz de garantir tal precisão, como geralmente acontece em pesquisas de levantamento survey.

Figura 2 - Modelo da Pesquisa

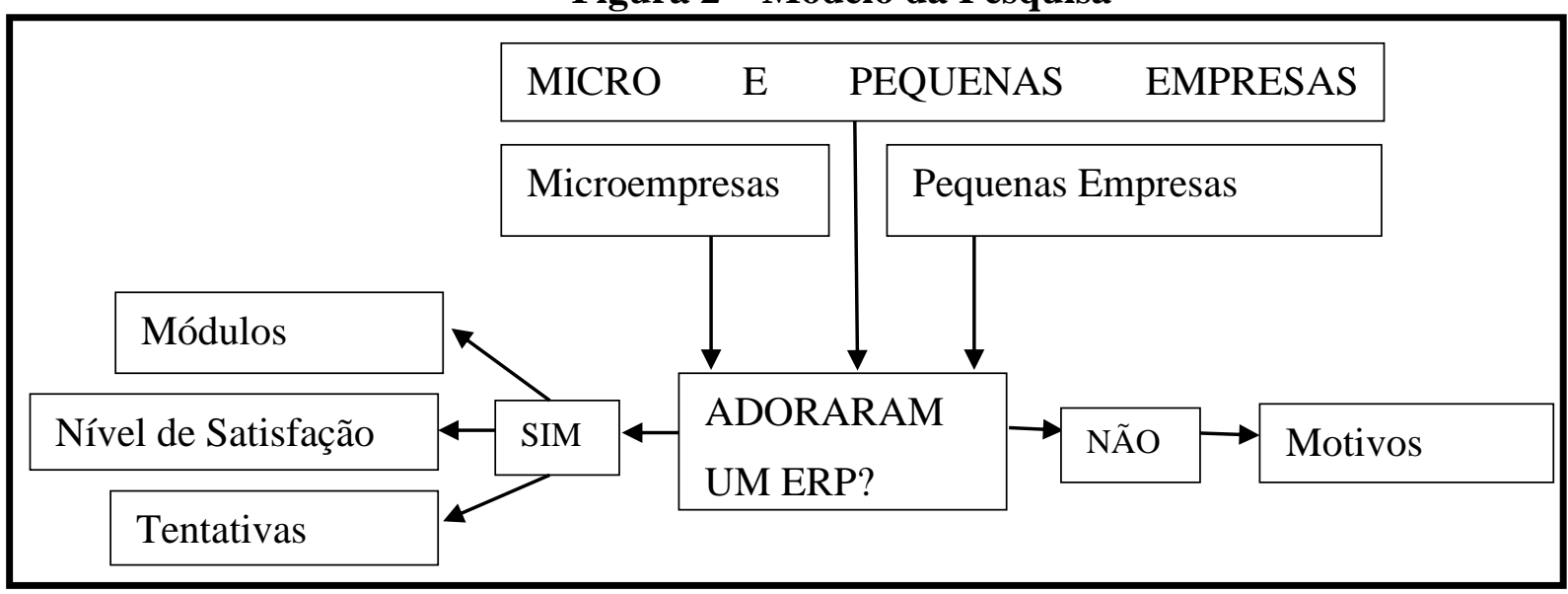

Fonte: Elaborada pelo autor.

A partir do instrumento de coleta previamente determinado, foi executada uma pesquisa piloto no dia 28/06/2016, tendo sido aplicados 10 questionários pela internet. Foi percebido um tempo médio de preenchimento em torno de 5 (cinco) minutos. Após o questionário ter sido preenchido, o pesquisador entrou em contato com cada pesquisado para medir o nível de satisfação quanto ao instrumento e as sugestões de melhoria para o mesmo. Dentre as sugestões de melhoria observada pelos pesquisados, pode-se destacar as seguintes contribuições: remover os campos Nome da Empresa, CNPJ e Telefone, pois expõem a empresa pesquisada; remover os campos Nome do Entrevistado, Telefone e E-mail, pois expõem o pesquisado. Após a análise das sugestões recebidas, foi formatado um novo questionário primando pelo anonimato das empresas e entrevistados.

O questionário foi aplicado das seguintes formas: 1) Internet: Utilizando a ferramenta Google Forms ${ }^{\circledR}$, escolhida por sua praticidade de acesso a pesquisa. O entrevistado recebia, por e-mail, um link que o direcionava para um formulário eletrônico, e com isso não precisava de nenhum software instalado; 2) Ligações Telefônicas: onde o entrevistado recebia uma ligação do entrevistador. O entrevistador se apresentava e fazia as perguntas descritas no questionário. Nesse momento, o mesmo preenchia o formulário de pesquisa, considerando as respostas do entrevistado, utilizando a ferramenta Google Forms ${ }^{\circledR}$.

Os entrevistados foram selecionados através de busca aleatória na internet. Para garantir uma representatividade mínima de cada Unidade da Federação no estudo, e assim reduzir a possibilidade de gerar um viés em relação aos estados e as regiões geográficas do país, foi considerado a relatividade das empresas existentes por estado, conforme dados do IBGE (2014), e através dessa relatividade foi rateado proporcionalmente a quantidade de questionários previstos a serem realizados.

Após a coleta dos dados, os mesmos foram tabulados de forma a transformá-los em informações, segundo os entrevistados. Os dados foram processados e cruzados de acordo com as variáveis e cálculos estatísticos proporcionando assim a realização dos testes de

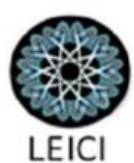


hipóteses. Para tanto, foram utilizadas planilhas eletrônicas (Excel®, software integrante do pacote Microsoft Office) e o software de análise estatística (IBM SPSS Statistic Versão 22®). Quanto às medições dos atributos em importância (atributos elencados de forma ordinal) foi utilizada análises de tendência central descritiva (médias, mediana e moda) e desvio (desvio padrão) conforme sugere Malhotra (2012), além do uso de tabelas cruzadas de dados e medidas de frequência.

\section{Resultados}

\subsection{Grau de Adoção de um sistema ERP}

\section{Gráfico 1 - Grau de adoção de um sistema ERP pelas MPE}
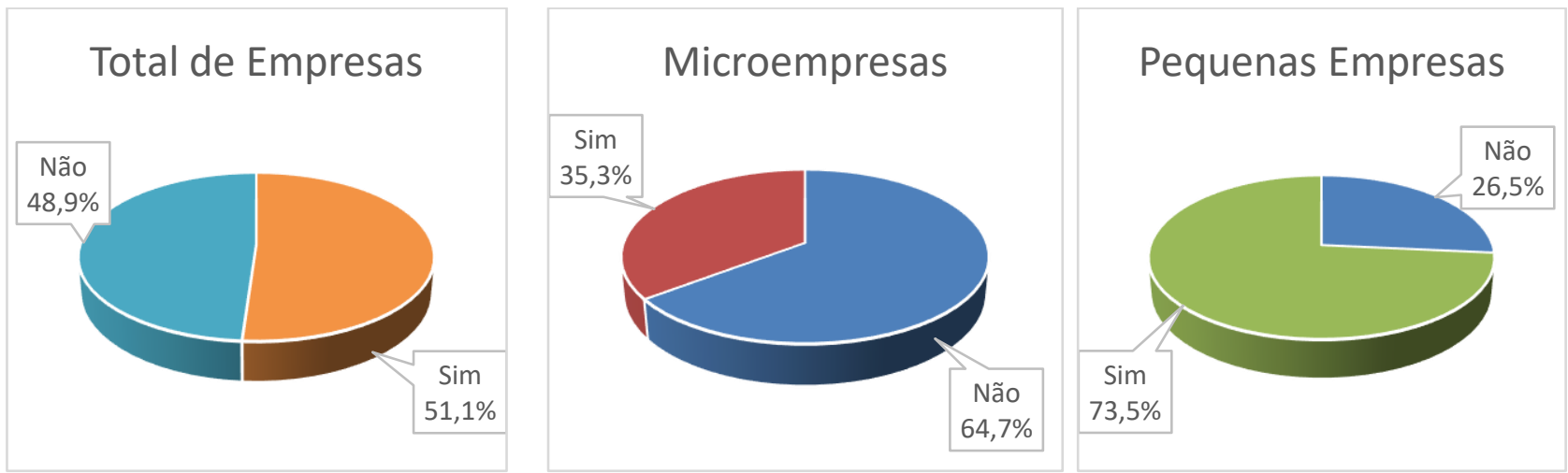

Fonte: Elaborado pelo autor.

Observando as MPE e a adoção de um sistema ERP, percebe-se que a quantidade de empresas que adotaram um sistema ERP representa um pouco mais da metade das empresas $(51,1 \%)$. Isso demonstra o potencial de MPE que ainda pode ser explorado na adoção dessas tecnologias e como a adoção de tais sistemas pode contribuir para aumentar a eficiência, otimizando a capacidade para fazer negócios em qualquer lugar (STAMFORD, 2000). No entanto, observando a relação entre as MPE, apenas 35,3\% das microempresas possuem um sistema ERP, contra 73,5\% das pequenas empresas. O uso do computador nas MPE tem se difundido de forma muito rápida, o que tem possibilitado vários empresários a utilização de diferentes ferramentas computacionais, vista por alguns como meio de destacar-se ante seus concorrentes, ou pelo menos manter-se competitivo (KUAN e CHAU, 2001), no entanto, o estudo demonstra que, no que tange as microempresas, ainda existe um grande gap da adoção dessas tecnologias $(35,3 \%-73,5 \%)$.

\subsection{Módulos adotados de um sistema ERP pelas MPE}

Com relação às empresas pesquisadas que informaram possuir um sistema ERP, foi medido os principais módulos que compõem o mesmo e o estágio de adoção de cada um. Considerou-se há aplicação do mesmo ao negócio, se está em processo de implementação ou se se está implementado. De acordo com a tabela 2, os módulos mais implementados nas microempresas, em ordem de adoção, são: Financeiro $(88,2 \%)$, Clientes $(87,1 \%)$, Orçamentos 
$(83,5 \%)$ e Estoque $(80 \%)$. E nas pequenas empresas são: Orçamentos $(77,6 \%)$, Financeiro $(75,2 \%)$ e Ponto de Venda (70,4\%). Quando observada a inaplicabilidade dos módulos, nas microempresas os módulos com maior inaplicabilidade são: Distribuição $(31,8 \%)$ e Produção (30,6\%). E nas pequenas empresas são: Clientes e Recursos Humanos (ambos com 29,6\%).

O estudo chama a atenção para as pequenas empresas com prioridade na adoção de módulos considerados como "gargalos" dos processos operacionais (Orçamentos, Financeiro e Ponto de Venda). De acordo com Mendes \& Escrivão (2002), a adoção de diversos módulos facilita a integração entre as várias áreas da empresa. Os usuários operam a mesma base de dados e utilizam a mesma informação. Após a implantação, espera-se o aumento do controle sobre as informações da empresa e a melhora sobre a administração do negócio, pois há mais confiabilidade nas informações armazenadas.

\subsection{Nível de satisfação das empresas adotantes de um ERP}

Considerando o Nível de Satisfação das empresas adotantes de sistemas ERP, é possível perceber, segundo os resultados obtidos, que a maioria das empresas está "Satisfeito" $(67,1 \%)$ ou "Totalmente Satisfeito" (26,2\%) com a adoção do sistema ERP e esse grau de satisfação repete a mesma tendência quando observado tanto para as microempresas quanto para as pequenas empresas, como pode ser visualizado na tabela 3 .

Destaca-se que a satisfação pode estar relacionada a utilidade percebida após a adoção (LUNARDI, DOLCI E MAÇADA, 2010), o que abre perspectivas para uma maior conscientização das empresas não adotantes em relação aos benefícios alcançados e o grau de satisfação. Por outro lado, se focalizar no total de adotantes "totalmente satisfeitos", observase que apenas $26,2 \%$ dos mesmos foram plenamente atendidos pela adoção do sistema ERP, direciona para a melhoria do processo de adoção desde a seleção até a absorção da tecnologia.

Tabela 2 - Módulos adotados pelas MPE

\begin{tabular}{|c|c|c|c|c|c|c|c|}
\hline & \multicolumn{2}{|c|}{ Microempresa } & \multicolumn{2}{|c|}{ Pequena Empresa } & \multicolumn{2}{|c|}{ Total } \\
\hline & & Contagem & $\begin{array}{c}\text { Relativo } \\
(\%)\end{array}$ & Contagem & \begin{tabular}{|c|}
$\begin{array}{c}\text { Relativo } \\
(\%)\end{array}$ \\
\end{tabular} & Contagem & $\begin{array}{c}\text { Relativo } \\
(\%)\end{array}$ \\
\hline \multirow[t]{3}{*}{ Orçamentos } & Não se aplica & 12 & $14,1 \%$ & 13 & $10,4 \%$ & 25 & $11,9 \%$ \\
\hline & Em Implantação & 2 & $2,4 \%$ & 15 & $12,0 \%$ & 17 & $8,1 \%$ \\
\hline & Implementado & 71 & $83,5 \%$ & 97 & $77,6 \%$ & $\begin{array}{r}16 \\
8\end{array}$ & $80,0 \%$ \\
\hline \multirow{3}{*}{$\begin{array}{l}\text { Ponto } \\
\text { Venda }\end{array}$} & Não se aplica & 20 & $23,5 \%$ & 25 & $20,0 \%$ & 45 & $21,4 \%$ \\
\hline & Em Implantação & 10 & $11,8 \%$ & 12 & $9,6 \%$ & 22 & $10,5 \%$ \\
\hline & Implementado & 55 & $64,7 \%$ & 88 & $70,4 \%$ & $\begin{array}{r}14 \\
3\end{array}$ & $68,1 \%$ \\
\hline \multirow[t]{3}{*}{ Distribuição } & Não se aplica & 27 & $31,8 \%$ & 30 & $24,0 \%$ & 57 & $27,1 \%$ \\
\hline & Em Implantação & 9 & $10,6 \%$ & 13 & $10,4 \%$ & 22 & $10,5 \%$ \\
\hline & Implementado & 49 & $57,6 \%$ & 82 & $65,6 \%$ & $\begin{array}{r}13 \\
1\end{array}$ & $62,4 \%$ \\
\hline \multirow[t]{3}{*}{ Clientes } & Não se aplica & 11 & $12,9 \%$ & 37 & $29,6 \%$ & 48 & $22,9 \%$ \\
\hline & Em Implantação & 0 & $0,0 \%$ & 11 & $8,8 \%$ & 11 & $5,2 \%$ \\
\hline & Implementado & 74 & $87,1 \%$ & 77 & $61,6 \%$ & $\begin{array}{r}15 \\
1\end{array}$ & $71,9 \%$ \\
\hline
\end{tabular}




\begin{tabular}{|llrrrrrr|} 
Recursos & Não se aplica & 22 & $25,9 \%$ & 37 & $29,6 \%$ & 59 & $28,1 \%$ \\
& Em Implantação & 12 & $14,1 \%$ & 12 & $9,6 \%$ & 24 & $11,4 \%$ \\
& Implementado & 51 & $60,0 \%$ & 76 & $60,8 \%$ & 12 & $60,5 \%$ \\
Estoque & Não se aplica & 11 & $12,9 \%$ & 35 & $28,0 \%$ & 46 & $21,9 \%$ \\
& Em Implantação & 6 & $7,1 \%$ & 3 & $2,4 \%$ & 9 & $4,3 \%$ \\
& Implementado & 68 & $80,0 \%$ & 87 & $69,6 \%$ & 15 & $73,8 \%$ \\
\multirow{3}{*}{ Produção } & Não se aplica & 26 & $30,6 \%$ & 24 & $19,2 \%$ & 50 & $23,8 \%$ \\
& Em Implantação & 5 & $5,9 \%$ & 16 & $12,8 \%$ & 21 & $10,0 \%$ \\
& Implementado & 54 & $63,5 \%$ & 85 & $68,0 \%$ & 13 & $66,2 \%$ \\
Financeiro & Não se aplica & 9 & $10,6 \%$ & 18 & $4,4 \%$ & 27 & $12,9 \%$ \\
& Em Implantação & 1 & $1,2 \%$ & 13 & $10,4 \%$ & 14 & $6,7 \%$ \\
& Implementado & 75 & $88,2 \%$ & 94 & $75,2 \%$ & 16 & $80,5 \%$ \\
\hline Total & & 85 & $100,0 \%$ & 125 & $100,0 \%$ & 210 & $100,0 \%$ \\
\hline
\end{tabular}

Fonte: Elaborado pelo autor.

Tabela 3 - Nível de satisfação em relação a adoção de um sistema ERP

\begin{tabular}{|lrrrrr|}
\hline & \multicolumn{6}{c}{ Nível de Satisfação para Adoção } & Total \\
& $\begin{array}{c}\text { Totalmente } \\
\text { insatisfeito }\end{array}$ & Insatisfeito & \multicolumn{2}{c}{ Satisfeito } & Totalmente \\
satisfeito & \\
Microempresa & 6 & 0 & 52 & 27 & 85 \\
$\%$ & $7,1 \%$ & $0,0 \%$ & $61,2 \%$ & $31,8 \%$ & $100 \%$ \\
Pequena Empresa & 8 & 0 & 89 & 28 & 125 \\
$\%$ & $6,4 \%$ & $0,0 \%$ & $71,2 \%$ & $22,4 \%$ & $100 \%$ \\
Total & 14 & 0 & 141 & 55 & 210 \\
$\%$ & $6,7 \%$ & $0,0 \%$ & $67,1 \%$ & $26,2 \%$ & $100 \%$ \\
\hline
\end{tabular}

Fonte: Elaborado pelo autor.

\subsection{Tentativas anteriores de adoção de um sistema ERP pelas MPE}

Conforme pode ser observado na tabela 4, 63,4\% $(36,2 \%+21,9 \%+4,3 \%+1 \%)$ das empresas entrevistadas já passaram pela experiência de adotar ao menos um sistema ERP antes do atual adotado. Esse percentual é sem dúvida alto, uma vez que, mesmo não sendo abordado os motivos de ter existido a necessidade de adotar outro sistema ERP, pode-se afirmar que houve o esforço para a adoção e depois a desistência, o que, por consequência, gera desperdício de investimentos, altos custos, retrabalhos, perda de tempo e de credibilidade dos colaboradores em relação a qualquer outra adoção de sistemas por terem participado de uma experiência fracassada. Além disso, é possível afirmar que 63,4\% das adoções de sistemas ERP não foram bem-sucedidas, considerando as premissas do processo de adoção abordados por Cribb et al. (2011), o qual culmina na absorção da tecnologia ao cotidiano da empresa. 
Tabela 4 - Quantidade de ERP já adotados nas micro e pequena empresas

\begin{tabular}{|crrrrrr|}
\hline & & \multicolumn{4}{c}{ Quantos ERP já adotou? } & \multicolumn{2}{c|}{ Total } \\
& $\mathbf{0}$ & $\mathbf{1}$ & $\mathbf{2}$ & $\mathbf{3}$ & $\mathbf{4}$ & \\
\hline \multirow{2}{*}{ Microempresa } & 36 & 21 & 25 & 3 & 0 & 85 \\
& $42,4 \%$ & $24,7 \%$ & $29,4 \%$ & $3,5 \%$ & $0,0 \%$ & $100,0 \%$ \\
\hline \multirow{2}{*}{ Pequena Empresa } & 41 & 55 & 21 & 6 & 2 & 125 \\
& $32,8 \%$ & $44,0 \%$ & $16,8 \%$ & $4,8 \%$ & $1,6 \%$ & $100,0 \%$ \\
\hline \multirow{2}{*}{ Total } & $\mathbf{7 7}$ & $\mathbf{7 6}$ & $\mathbf{4 6}$ & $\mathbf{9}$ & $\mathbf{2}$ & $\mathbf{2 1 0}$ \\
& $\mathbf{3 6 , 7 \%}$ & $\mathbf{3 6 , 2 \%}$ & $\mathbf{2 1 , 9 \%}$ & $\mathbf{4 , 3} \%$ & $\mathbf{1 , 0} \%$ & $\mathbf{1 0 0 , 0} \%$ \\
\hline
\end{tabular}

Fonte: Elaborado pelo autor.

\subsection{Motivos para não adotaram um sistema ERP}

Foi observado que 48,9\% das MPE ainda não adotaram um sistema ERP, e com base nessa afirmação, foi pesquisado o motivo pelo qual tais empresas ainda não adquiriram. Conforme pode ser observado na tabela 5, destaca-se as seguintes justificativas: a) Não tenho condições financeiras para investir $(33,8 \%)$. Isso sugere a adoção de um sistema ERP é vista como um custo e não um investimento e que políticas de incentivo por parte do governo devam ser fomentadas para viabilizar tais tecnologias para as MPE. b) Faço meu controle através de planilhas $(31,8 \%)$. O que abre a perspectiva para o aumento da eficiência das empresas através das integrações do setores e redução dos retrabalhos, o que não é possível através de planilhas eletrônicas. Cabe destacar que essas justificativas geram questionamentos em relação a identificação dos benefícios (tangíveis e intangíveis), custos x benefícios e principais riscos da adoção ou falta dela que podem estar sendo deixados de lado (LOVE et al, 2005).

Tabela 5 - Justificativas para não adotar um sistema ERP

\begin{tabular}{|c|c|c|c|c|c|c|}
\hline \multirow{2}{*}{ Justificativas } & \multicolumn{2}{|c|}{ Microempresa } & \multicolumn{2}{|c|}{ Pequena Empresa } & \multicolumn{2}{|l|}{ Total } \\
\hline & Contagem & $\begin{array}{l}\text { Relativo } \\
\text { (\%) }\end{array}$ & Contagem & $\begin{array}{l}\text { Relativo } \\
(\%)\end{array}$ & Contagem & $\begin{array}{l}\text { Relativo } \\
(\%)\end{array}$ \\
\hline $\begin{array}{l}\text { Não tenho condições } \\
\text { financeiras para investir }\end{array}$ & 55 & $35,3 \%$ & 13 & $28,9 \%$ & 68 & $33,8 \%$ \\
\hline $\begin{array}{l}\text { Faço meus controles através } \\
\text { de planilhas }\end{array}$ & 53 & $34,0 \%$ & 11 & $24,4 \%$ & 64 & $31,8 \%$ \\
\hline Não vejo necessidade & 30 & $19,2 \%$ & 4 & $8,9 \%$ & 34 & $16,9 \%$ \\
\hline Outros & 13 & $8,3 \%$ & 10 & $22,2 \%$ & 23 & $11,4 \%$ \\
\hline $\begin{array}{l}\text { Não conheço uma empresa de } \\
\text { confiança }\end{array}$ & 5 & $3,2 \%$ & 7 & $15,6 \%$ & 12 & $6,0 \%$ \\
\hline
\end{tabular}


Fonte: Elaborado pelo autor.

\section{Considerações Finais}

Os resultados apresentados não são suficientes para tecer considerações conclusivas sobre a adoção de sistemas ERP nas MPE brasileiras, porém dão uma ideia de como está o processo de adoção. A pesquisa apresentada demandou um extenso esforço para a elaboração e validação de um instrumento capaz de diagnosticar o grau de adoção dos sistemas ERP nas MPE brasileiras, e com isso possibilitou-se algumas reflexões a partir da constatação que apenas $51,1 \%$ das empresas estudadas possuem um sistema ERP, gerando assim uma grande oportunidade de avanço tecnológico, eficiência e melhorias dos processos para quase a metade das MPE brasileiras. Foi constatado que esse número se agrava muito mais, quando se observa o universo das microempresas, onde apenas 35,3\% delas possuem um sistema ERP. Nesse contexto, incentivos para a adoção desses sistemas podem ser considerados como uma medida a ser aplicada, uma vez que a "falta de recursos financeiros" foi apontada como uma das principais razões da não adoção. Além disso, políticas de conscientização e informação sobre os benefícios dessas tecnologias também devem ser fomentadas.

Quanto aos módulos adotados pelas MPE observou-se a prioridade para os módulos Financeiro, Orçamentos, Estoque e Clientes em detrimento a outros módulos como Relacionamento com Clientes, Vendas, Caixa e Tesouraria. Mesmo que a adoção não tenha sido estimulada pelo retorno esperado, a adoção dos demais módulos que compõem um sistema ERP abre perspectiva para o avanço tecnológico, aumento da eficácia e maximização dos resultados. Uma vez que os módulos aplicados já demonstração um alto índice de satisfação por parte dos adotantes.

Os resultados e as implicações obtidas neste estudo devem levar em conta alguns cuidados no que diz respeito, especialmente, à amostra estudada, a qual foi selecionada de forma a generalizar as MPE brasileiras. No entanto, sugere-se estudos futuros considerando amostras regionalizadas, setores específicos da economia, determinadas regiões do país e até mesmo estudo com foco exclusivo nas microempresas ou pequenas empresas.

O estudo também abre perspectiva para novos estudos a fim de explorar os impactos da adoção de tecnologias nos resultados das empresas, seus benefícios e restrições. Dessa forma, a adoção de sistemas ERP poderá exercer impacto ainda maior no desempenho dessas organizações, justificando assim a realização de tais investimentos.

\section{Referências Bibliográficas}

Addo, R. (2011, October). Article: Enterprise Resource Planning (ERP): A Review Literature Report. The World Congress on Engineering and Computer Science 2011 Vol II WCECS 2011, San Francisco, USA.

Almeida, Juliano, et al. (2012). A utilização da contabilidade como ferramenta de apoio à gestão nas MPE do ramo de comércio de material de construção de Feira de Santana/BA. Revista da Micro e Pequena Empresa, nº 6.2 p. 89-106.

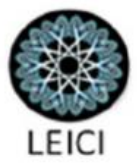


Banco Nacional de Desenvolvimento Econômico e Social - BNDES (2010). Circular 11/2010 para definição do Porte das empresas. Recuperado em 25 de abril, 2015, de http://www.bndes.gov.br/SiteBNDES/bndes/bndes_pt/Institucional/Apoio_Financeiro/porte.ht ml.

Batista, \& Emerson O. (2013). Sistemas de Informação: o uso consciente da tecnologia para o gerenciamento. $2^{\text {a }}$ ed. São Paulo. Editora Saraiva.

Barbetta, P. A. (2010). Estatística Aplicada às Ciências Sociais. Editora UFSC. $7^{\mathrm{a}}$ ed. revisada, Florianópolis.

Chopra, S., \& Meindl. (2016). Gerenciamento da Cadeia de Suprimentos - Estratégia, Planejamento e Operação. $6^{\mathrm{a}}$ ed. Prentice Hall.

Cohen, W. L., \& Levinthal, D. A. (1990). Absorptive capacity: a new perspective on learning and innovation. Administrative Science Quarterly, Ithaca, v. 35, n. 1, p. 128-152.

Cribb, A. Y. (2009). Determinantes da transferência de tecnologia na agroindústria brasileira de alimentos: identificação e caracterização. Journal of Technology Management and Innovation, Santiago, v. 4, p. 89-100.

Cribb, A. Y., Cribb, S. L., Freire, M. F. Jr., \& Silva, F. T. (2011). Adoção Tecnológica e Gestão Cooperativista: Um estudo de caso na Agricultura Familiar. Cadernos de Ciência \& Tecnologia, Brasília, v. 28, n. 1, p. 133-157, jan./abr.

Davenport, T. H. (2000). Mission critical: realizing the promise of enterprise systems. Boston, Massachusetts: Harvard Business School Press.

Domínguez, M. C. H., Aranda, D. A., Montes, F. J., \& Moreno, A. R. (2007). The impact of absorptive capacity on technological acquisitions engineering consulting companies. Technovation, Amsterdam, v. 27, n. 8, p. 417-425.

Freitas, H., \& Reich, I. (2003). Problemas e ações na adoção de novas tecnologias de informação. Revista de Administração Contemporânea, São Paulo, v.7, n.1, p.125-149.

Instituto Brasileiro de Geografia e Estatística - IBGE (2016). Estatísticas do cadastro central de empresas: 2014, Coordenação de Metodologia das Estatísticas de Empresas, Cadastros e Classificações. - Rio de Janeiro: IBGE.

Hausman, A., \& Stock, J. R. (2003). Adoption and implementation of technological innovations within long-term relationships. Journal of Business Research, New York, v. 56, n. 8, p. 681-686.

Hu, Q., \& Plant, R. (2001). An empirical study of the casual relationship between IT investment and firm performance. Information Resources Management Journal, USA, v.14, n.3, p.15-26, July/September.

Laudon, Kenneth C.; \& Laudon, J. (2014). Sistemas de informação gerenciais: administrando a empresa digital. São Paulo: Pearson Education do Brasil.

Lima, P. (2007, Julho). Barradas na festa. Revista Amanhã, Porto Alegre, ano 21, n.233, p.4251.

Love, P. (2005, October). The enigma of evaluation: benefits, costs and risks of IT in Australian small-medium-sized enterprises. Information \& Management, Netherlands, v.42, n.7, p.947-964.

Lunardi, G., Dolci, P., \& Maçada, A. (2010). Adoção de tecnologia de informação e seu impacto no desempenho organizacional: um estudo realizado com micro e pequenas empresas. Revista de Administração da USP, v.45, n.1, p.5-17.

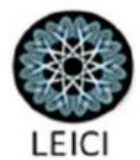


Kuan, K., \& Chau, P. (2001, October). A perception-based model of EDI adoption in small businesses using technology-organizationenvironment framework. Information \& Management, Netherlands, v.38, n.8, p.507-521.

Malhotra, N. K. (2012). Pesquisa de marketing: uma orientação aplicada. 6 Ed., Bookman Editora.

Mcafee, A. (2004, April). Do you have too much IT? MIT Sloan Management Review, USA, v.45, n.3, p.18-22.

Mendes, J. V., \& Escrivão, E. F. (2000). O sistema integrado de gestão é fator de competitividade para as pequenas e médias empresas? Revista Uniara, n. 8, p. 13-21.

Mendes, J. V., \& Escrivão, E. F. (2002, Dezembro). Sistemas Integrados de Gestão (ERP) em Pequenas Empresas. Revista Gestão \& Produção, v.9, n.3, p.277-296.

Moraes, G., Terence, A., \& Escrivão, E. F. (2004). A tecnologia de informação como suporte à gestão estratégica da informação na pequena empresa. Revista de Gestão da Tecnologia e Sistemas de Informação, São Paulo, v.1, n.1, p.28-44.

Oliveira, R. C. R., Santos, E. M., \& Gonzalez, I. P. Jr. (2013). Uma proposta para análise da adoção de tecnologias da informação em micro e pequenas empresas a partir da adaptação do modelo TOE (Technology, Organization and Environment). Revista Brasileira de Administração Científica, Aquidabã, v.4, n.2, p.257-272.

Oliveira, T., \& Martins, M. (2011). Literature Review of Information Technology Adoption Models at Firm Level. The Electronic Journal Information Systems Evaluation, v.14, n.1, p.110-121.

Pisano, G. P. (1990). The R\&D boundaries of the firm: an empirical analysis. Administrative Science Quarterly, Ithaca, v. 35, n. 1, p. 153-176.

Porter, M. E. (1999). Competição: estratégias competitivas essenciais. Rio de Janeiro: Ed. Campus.

Receita Federal. (2017). Portal do SPED recuperado em 02 de novembro de 2017 em http://sped.rfb.gov.br/.

Rogers, E. M. (2003). Diffusion of innovations. 5th Edition. New York: Free Press.

Serviço Brasileiro de Apoio às Micro e Pequenas Empresas - SEBRAE (2014). Participação das Micro e Pequenas Empresas na Economia Brasileira. SEBRAE.

Souza, C. A., \& Zwicker, R. (2000, Setembro) Implementação de Sistemas ERP: um estudo de casos comparados. Anais do $24^{\circ}$. Encontro da ANPAD. Florianópolis.

Stamford, P. P. (2014). ERP's: prepare-se para esta mudança. Artigo publicado pela KMPress. Recuperado em 05 de janeiro de 2014 em http://www.kmpress.com.br. 